\section{Disinformation in the information age}

\author{
Yared González-Pérez
}

\section{INTRODUCTION}

The emergence of disruptive new technologies such as the internet, web 2.0, and social media have allowed us to bring about a clear change in society, as they have opened up new channels of communication that didn't exist before. This revolution brings with it new ways to access, produce, communicate, and share information in milliseconds.

This social change has accelerated with the emergence of mobile smart devices known as smartphones, because simply adding to these internet devices has managed to orient us to a social environment that is connected in a synchronous way, in real time, in a data-generating environment, on an ongoing basis, and has democratised the use of, and access to, knowledge in this new digital environment.

People use social media to discuss different topics of interest, including healthcare: even health professionals take advantage of social media to share information, promote healthy behaviours, and educate and interact with patients. ${ }^{1}$

There are certainly benefits to using these technologies. However, they have also enhanced a problem already known for centuries: the dissemination of news with low scientific rigour, false information, or rumours that have the power to generate a state of disinformation among readers. $^{2}$

\section{CONTEXTUALISATION OF THE PROBLEM}

A lot of misinformation currently circulating in the network is shared, goes viral, and can be even more popular than true information that is scientifically backed. If we analyse the content of this information, we find that it is usually characterised by personal opinions and evocation of negative feelings. These publications manage to influence cognitive and emotional aspects, triggering states of fear, panic, anxiety, mistrust, and hope, among others. ${ }^{1}$

Digital channels have developed participatory social communication pathways, through which new friendships are made

Hospital Pharmacy, Hospital San Pedro, Logroño, La Rioja, Spain

Correspondence to Dr Yared González-Pérez, Hospital Pharmacy, Logroño, Spain; yaredgpz@gmail. com and connections strengthened via online interaction. In such cases, individuals who are very active in influencing the opinions of their communities enjoy greater popularity and acceptance than evidence-based information. ${ }^{3}$

Furthermore, in recent years, influencers of social networks have appeared, who are able to persuade others because they possess skills such as sympathy, nearness, familiarity, reliability, or experience. Their opinion leadership is such that they are able to viralise any information on social media. ${ }^{45}$

Typical topics of disinformation hosted on the web relate to health issues, physical exercise, and nutrition. In the specific case of health issues, the most common is information without scientific rigour on contagious diseases such as Human Papillomavirus, Zika, Ebola, measles, or influenza and aspects as important as cancer, vaccination, or the use of antibiotics. These provide clear examples of dissemination of theories without rigour on Facebook or Twitter such as the refusal to vaccinate children that is based on the fear of the development of autism. ${ }^{67}$

When news circulates repeatedly ${ }^{8}$ and is finally accepted and shared, there is a positive relationship between the credibility of the news and the inability to critically process and value information to finally share it in the digital environment, that is, we are dealing with people with low health literacy. ${ }^{9}$ The result is a detrimental risk to individual and collective health and social wellness.

To date, there have not been quality studies that adequately evaluate the reasons for such viralisation of news that generates misinformation states in the population. However, a review of Talwar et $\mathrm{al}^{3}$ discusses aspects that can influence the dark side of social networks. On the one hand, it should be noted that the volume and speed at which this information is transmitted conditions a certain difficulty in detecting its credibility quickly. On the other hand, psychosocial aspects that can be correlated, from a negative point of view, with the inability to assess the credibility of news and, from a positive point of view, with sharing it are: excessive trust in other individuals on the Web; a sense of belonging to a social group; fear of being left out; self-disclosure of personal information on the network in the face of the need to make and improve social connections; strengthened relationships; as well as the presence of exciting and/or sensational news shared by popular people in one's digital environment; or fatigue associated with the use of such social networks that leads to states of disappointment, sadness, anger, or reduced energy.

\section{STRATEGIES FOR ATTEMPTING TO FIX THIS REAL PROBLEM}

The dissemination and viralisation of such news is considered a serious public health problem, given that they can trigger treatment abandonment, ${ }^{10}$ negativity towards vaccination recommendation, ${ }^{11}$ or the choice of alternative treatments without scientific basis such as homeopathy ${ }^{12}$ for the cure of cancer, among other diseases. ${ }^{10}$

In view of the importance of this issue, there is a need to address how to solve this great problem of the 21 st century. In Spain, specifically, the first guide to countering disinformation in the ambulatory care system has appeared. ${ }^{13}$ It provides four useful recommendations for the day-to-day:

\section{Recommendation 1: prescribe reliable websites}

It is necessary, in practice, to prescribe reliable digital content, owing to the excess of information available on the internet, which makes it difficult to distinguish between scientifically accurate and unfounded content. In other words, the aim is to guide the patient towards sites that provide truthful, contrasted, and accredited information.

A reliable page, channel, blog, or website must have at least the following characteristics: a visible author, with contact information; a contributed bibliography with which to contrast the information (always consult several sources; do not believe in miraculous solutions); little or no advertising (suspect the site if there is excessive advertising); and some quality mark of its endorsement by a health institution.

Furthermore, the first page of search engines (eg, Google) does not always provide first-quality, updated information, because it expires (see figure 1).

\section{Recommendation 2: disseminate truthful and contrasted information}

Digital channels should be communication channels that use simple, adapted language, without technical terms, that is understandable but does not diminish scientific rigour. The aim is to disseminate verified information and improve access to, and quality of, this information. 
UPDATED INFORMATION Information expires

Q IDENTIFY AUTHORS

- Is he or she a professional expert on the subject?

- Information references

- Can the author be contacted? $\infty$ $\Longleftrightarrow$ DO NOT TRUST IF

- Excessive advertising

- Talk about miracle remedies FIRST PAGE OF GOOGLE

Be careful, this does not mean of high quality
SOURCES OF INFORMATION

It takes more than one

CHECK

How your data will be treated

TRUSTED SITES

- Guaranteed scientific rigor

- Quality seals

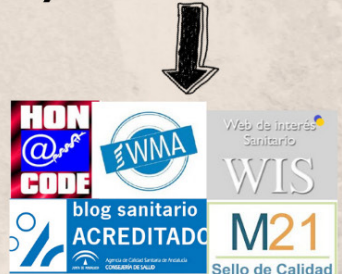

\section{The Internet is a complementary tool to the information provided by healthcare professionals}

Figure 1 How to recognise credible websites, extracted and adapted from the first guide against hoaxes in primary care. Spanish Society of General Practitioners and Family Doctors.

This strategy can successfully position a professional on the internet, thereby improving his or her digital reputation and generating a bond of trust. In addition, an attractive, visual format is important to provoke interest and encourage patients to share such information with their communities.

Recommendation 3: orient the patient in the consultation

Consultation time is limited. However, when faced with a question about untrue news, it is necessary to develop a series of mechanisms to prevent the dissemination of such questionable information: one should adopt a favourable attitude towards the internet and social networks; emphasise that a belief in miracle solutions (eg, cancer cures) or alarmist news (eg, adverse drug reactions) should be avoided; teach how to identify truthful content (as suggested in recommendation 1); and, finally, direct the individual to reliable sources.

To reduce false beliefs and improve the health professional-patient relationship, it is essential, throughout the process, to demonstrate active listening and empathy, and to use simple language with scientifically supported data or arguments.
Recommendation 4: be a reference for the patient on social networks

The reality in which we currently live is developed in an environment in which both patients and professionals use social networks (Twitter, Facebook, etc.) to share information about health, medicines, illnesses, etc. It is therefore important to transform the role of the health professional into that of an active professional 2.0 in these digital channels, informing and disseminating truthful information or dismantling myths, falsehoods, or inappropriate news. It is similar to the doctor, nurse or pharmacist of reference that the patient sees in consultations in a hospital or health centre. In this case, in the digital world, it is necessary for someone with guarantees of reliability and veracity to follow-up and ask questions.

\section{REGARDING THE HOSPITAL PHARMACY}

Hospital pharmacists, like other healthcare professionals, play an important role in the healthcare system. We must respond to the problematic situation presented by this new digital environment and, to do so, we must acquire digital skills ${ }^{14}$ such as managing, producing, and sharing knowledge, to generate a message that reaches far beyond the hospital.
It is necessary to take action by promoting health literacy among citizens, educating them about healthy lifestyles, denying false information through the use of available tools, advocating for transparent news, and collaborating with other professionals, with the aim of solving this growing problem on the web, of which every person in society can be a victim.

Twitter Yared González-Pérez @Yaredgp

Funding The authors have not declared a specific grant for this research from any funding agency in the public, commercial or not-for-profit sectors.

Competing interests None declared.

Provenance and peer review Not commissioned; internally peer reviewed.

(c) European Association of Hospital Pharmacists 2020. No commercial re-use. See rights and permissions. Published by BMJ.

A Check for updates

To cite González-Pérez Y. Eur J Hosp Pharm 2020;27:319-321.

Published Online First 24 January 2020

Eur J Hosp Pharm 2020;27:319-321. doi:10.1136/ejhpharm-2020-002213

\section{ORCID iD}

Yared González-Pérez http://orcid.org/0000-00017452-2205 


\section{REFERENCES}

1 Grajales III FJ, Sheps S, Ho K, et al. Social media: a review and tutorial of applications in medicine and health care. J Med Internet Res 2014;16:e13.

2 McKee M, van Schalkwyk MCl, Stuckler D. The second information revolution: digitalization brings opportunities and concerns for public health. Eur J Public Health 2019;29:3-6.

3 Talwar S, Dhir A, Kaur P, et al. Why do people share fake news? Associations between the dark side of social media use and fake news sharing behavior. $J$ Retail Cons Ser 2019;51:72-82.

4 Martensen A, Brockenhuus-Schack S, Zahid AL. How citizen influencers persuade their followers. J Fash Mrkt Mgt 2018;22:335-53.

5 Bakshy E, Hofman JM, Mason WA, et al. Everyone's an influencer: quantifying influence on Twitter. En: Proceedings of the fourth ACM international conference on Web search and data mining - WSDM
11 [Internet]. Hong Kong, China: ACM Press, 2011. Available: http://portal.acm.org/citation.cfm?doid= 1935826.1935845 [Accessed 13 Nov 2019].

6 Wang Y, McKee M, Torbica A, et al. Systematic literature review on the spread of health-related misinformation on social media. Soc Sci Med 2019;240:112552.

7 Fernández-Luque L, Bau T. Health and social media: perfect storm of information. Healthc Inform Res 2015:21:67-73.

8 Naveed N, Gottron T, Kunegis J, et al. Bad news travel fast: a content-based analysis of interestingness on Twitter. En: Proceedings of the 3rd International Web Science Conference on - WebSci '11 [Internet]. Koblenz, Germany: ACM Press, 2011. Available: http:// dl.acm.org/citation.cfm?doid=2527031.2527052 [Accessed 13 Nove 2019].

9 Wang Y. Systematic review on the social mechanism of health misinformation dissemination in the Internet era. Eur J Public Health 2018;28.
10 Soška V, Kyselák O. Some causes of poor adherence to long-term statin therapy and their solution. Vnitr Lek Fall de 2018;64:923-7.

11 Bozzola E, Spina G, Russo R, et al. Mandatory vaccinations in European countries, undocumented information, false news and the impact on vaccination uptake: the position of the Italian Paediatric Society. Ital J Pediatr 2018:44:67.

12 The Lancet Oncology. Oncology, "fake" news, and legal liability. Lancet Oncol 2018;19:1135.

13 I Guía contra los bulos en atención primaria. Sociedad Española de médicos Generales Y de familia. Available: https://www.semg.es/images/stories/recursos/2019/ documentos/1_guia_contra_los_bulos_en_ap.pdf [Accessed 25 Nov 2019].

14 Montero Delgado JA, Monte Boquet E, Cepeda Diez JM, et al. Las seis competencias digitales de los profesionales sanitarios [internet]. Farmacia Hospitalaria Digital, 2019. Available: https://www.farm aciahospitalariadigital.com [Accessed 1 Dec 2019]. 